\title{
Soldagem Helicoidal de Tubos Produzida em Campo do Aço ASTM A-1018 e sua Correlação com Características Mecânicas e Microestruturais das Juntas Soldadas*
}

\author{
Ana Carla Santos da Silva ${ }^{1}$, Erike Wilker Arruda Figueredo ${ }^{1}$, Deusdedit Carlos da Silva Júnior ${ }^{1}$, Tahiana Francisca da \\ Conceição Hermenegildo ${ }^{1}$, Tiago Felipe de Abreu Santos ${ }^{1}$ \\ ${ }^{1}$ Universidade Federal de Pernambuco - UFPE, Departamento de Engenharia Mecânica, Recife, PE, Brasil.
}

Recebido: 15 Jan., 2018

Aceito: 15 Out., 2018

E-mail: tiago.felipe@ufpe.br (TFAS)

\footnotetext{
* Contribuição para XLIV CONSOLDA Congresso Nacional de Soldagem sob título: "Características Geométricas e Microestruturais de Juntas Soldadas por Costura Helicoidal em Campo do Aço ASTM-A1018"
}

Este é um artigo publicado em acesso aberto (Open Access) sob a licença Creative Commons Attribution Non-Commercial, que permite uso, distribuição e reprodução em qualquer meio, sem restriçōes desde que sem fins comerciais e que 0 trabalho original seja corretamente citado.
Resumo: Um problema diversas vezes encontrado na produção de tubos está relacionado ao seu transporte dificultado por suas grandes dimensões. Atrelado a isso, a soldagem de campo é complexa e muitas vezes onerosa. Um processo de fabricação alternativo para tubulações é o processo de formação de tubos com costura helicoidal. Este trabalho propõe estudar as características microestruturais e realizar uma avaliação mecânica destas soldas executadas em campo do aço ASTM A1018. Para alcançar o objetivo do trabalho foram utilizados dois tubos de aço fabricados com chapas de espessura de $12,5 \mathrm{~mm}$ e diâmetro nominal de $1200 \mathrm{~mm}$, através do equipamento adaptado para a soldagem em campo pelo processo de soldagem por arco submerso. Após soldagem dos tubos, foram retiradas amostras destes para efetuar as análises de micrografia, macrografia, composição química, dobramento e dureza. A principal diferença apresentada entre as amostras foi o aumento da ferrita acicular e redução da ferrita primária de contorno de grão com o decréscimo do aporte térmico nas microestruturas formadas tanto na zona fundida como na ZTA como apresentado. Observou-se, ainda, mudanças na geometria dos cordões de solda. Por fim, identificou-se que o principal parâmetro que influência nas mudanças microestruturais apresentadas é a corrente de soldagem.

Palavras-chave: Tubos helicoidais; Soldagem por arco submerso; Caracterização microestrutural e mecânica.

\section{Helical Welding of ASTM A-1018 Steel Tubes Produced in Field and its Correlation with Mechanical and Microstructural Characteristics of Welded Joints}

\begin{abstract}
A problem commonly found in the production of tubes is related to transportation due its large dimensions. This fact, makes field welding a complex and often costly operation.. An alternative fabrication process for pipes is the process of forming tubes with helical welds. This work proposes to study the microstructural characteristics and perform a mechanical evaluation of these welds performed in field of ASTM A1018 steel tubes. In order to reach the aim, two steel tubes manufactured from sheets with a thickness of $12.5 \mathrm{~mm}$ and a nominal diameter of $1200 \mathrm{~mm}$ were welded by the process of submerged arc welding through the equipment adapted for field welding. Subsequently, samples were taken to perform characterization by microanalysis. Chemical composition, bending and hardness tests were also conducted. The main difference between the samples was the increase of the acicular ferrite and reduction of the primary ferrite of the grain boundary with the decrease of the thermal contribution in the microstructures formed in the molten zone as in the ZTA as presented. Also, changes in the geometry of the weld beads were observed. Finally, it was identified that the main parameter that influences the microstructural changes presented is the welding current.
\end{abstract}

Key-words: Helical tubes; Submerged arc welding; Microstructural and mechanical characterization.

\section{Introdução}

A soldagem é um dos métodos de união de materiais mais importantes na indústria [1,2]. A busca pela melhoria da sua qualidade tem sido um contínuo desafio nas indústrias metal mecânica, civil, de óleo e gás, dentre outras, com a exploração de novos processos e técnicas de soldagem. Com o desenvolvimento industrial, o uso de instalações metálicas em geral tem sido cada vez mais frequente e no último século tem ampliado a utilização de estruturas metálicas em todo o mundo, incluindo nesses tipos de estruturas 
Soldagem Helicoidal de Tubos Produzida em Campo do Aço ASTM A-1018 e sua Correlação com Características Mecânicas e Microestruturais das Juntas Soldadas

as tubulações industriais de grande diâmetro [3,4]. Tubos podem ser fabricados com ou sem costura. Nos tubos com costura, a soldagem é utilizada como recurso para o processo de manufatura. Os tubos com costura são obtidos através da conformação a frio de chapas planas ou bobinas de aço em um formato cilíndrico, podendo a solda ser realizada longitudinal ou helicoidal, com o uso ou não de metal de adição. Partindo desse ponto, na fabricação e montagem de tubos de aço, a soldagem se mostra como processo imprescindível [5-7].

Dentre os processos de soldagem mais utilizados para a fabricação de tubulação estão o eletrodo revestido (SMAW) e a soldagem por arco submerso (SAW) [8]. Apesar de apresentar ampla utilização por ser relativamente simples e aplicável em todas as posições de soldagem, o processo de soldagem por eletrodo revestido apresenta produtividade limitada quando comparada aos processos automáticos, tornando o processo SAW o mais utilizado devido à fatores como: alta taxa de deposição, alcance de altas velocidades de soldagem, elevada eficiência energética do processo, e facilidade de automatização $[6,7,9]$. Essas vantagens tornam o processo um dos mais presentes em pesquisas e desenvolvimento tanto no segmento industrial como no acadêmico e um dos métodos de soldagem preferível na produção de tubos de grandes diâmetros [7,10]. Visando o aumento da produtividade na fabricação de tubos metálicos de aço os processos de soldagem são cada vez mais refinados, ou ainda tem se tornado comum o emprego de combinações de processos de soldagem para que apresentem maior taxa de deposição e alta qualidade da solda.

Como processo alternativo de fabricação para tubulações, vem sendo usado hoje o processo de fabricação de tubos com costura helicoidal por soldagem a arco submerso [11]. De acordo com Alobaidi e Sandgren [12] e Sadowski e Rotter [13], esse processo de fabricação reduz em muitas vezes o custo com transporte, além de possibilitar a fabricação contínua de tubos com tamanhos maiores do que os comercialmente produzidos. Vantagens como a utilização da mesma largura de bobinas de aço em estoque que pode ser adaptada para construir tubos de vários comprimentos e diâmetros distintos não sendo necessários maiores investimentos para configuração diferente numa mesma produção de tubos, o tornam uma excelente opção no requisito aumento de produtividade e redução de custos. A fabricação de tubos com costura helicoidal em campo - para uso na construção civil como camisas metálicas - vem sendo desenvolvida atualmente pela empresa MEMPS através do equipamento sobre patente PI0802712-9 A2 [14]. A utilização dessa técnica traz vantagens para o processo produtivo de tubulação, pois agrega os fatores de aumento de produtividade, redução de custos e o alcance de propriedades mecânicas desejáveis em um único projeto [12,13,15].

Na soldagem por fusão, particularmente no processo SAW, trabalha-se com fontes de calor com alto aporte térmico. Esta transferência de calor da fonte para a junta gera gradientes de temperatura na solda e nas regiões adjacentes ao metal de base [8,16-18]. Assim, durante a soldagem com altas taxas de resfriamento, pode haver transformações microestruturais que promovem fragilização localizada e diminuem a tenacidade na ZTA, principalmente na região de grãos grosseiros (ZTAGG), pois a formação dos microconstituintes deletérios, em especial da martensita, é influenciada pelos ciclos térmicos de soldagem, particularmente em processos altamente fora do equilíbrio termodinâmico [2,18]. Para melhorar a tenacidade à fratura na ZTA, são selecionados procedimentos de soldagem que possam promover o aumento do percentual de microestruturas mais tenazes, como a ferrita acicular (AF) e algumas morfologias de bainita. Além da ZTA, o metal de solda também pode apresentar uma granulação grosseira, o que não é necessariamente prejudicial à tenacidade, desde que haja predominantemente ferrita acicular nesta região. Assim, pode-se considerar que tanto a microestrutura do metal de solda quanto a da ZTA dependem, da composição química dos consumíveis, dos parâmetros, procedimentos e processos de soldagem utilizados [16,17].

Nesse contexto, o objetivo desse trabalho foi avaliar as características mecânicas e microestruturais presentes em soldas realizadas pelo processo de soldagem a arco submerso com costura helicoidal em campo com o uso de dois conjuntos de parâmetros, considerando a influência da variação destes na produtividade deste processo.

\section{Materiais e Métodos}

O material base do estudo foi o aço estrutural ASTM A1018 SS 36 T2 cuja composição química e propriedades mecânicas fornecidas pelo fabricante são apresentadas na Tabela 1.

A Figura 1 apresenta a microestrutura do aço ASTM A-1018, utilizado como metal de base dos corpos de prova. Observa-se uma microestrutura constituída por grãos de ferrita e perlita fina. O carbono equivalente apresentado 
Tabela 1. Composição química (\%) e propriedades mecânicas do metal de base fornecidas pelo fabricante.

\begin{tabular}{cccccccc}
\hline $\mathbf{C}$ & $\mathbf{M n}$ & $\mathbf{S i}$ & $\mathbf{P}$ & $\mathbf{S}$ & $\mathbf{A l}$ & $\mathbf{C r}$ & Mo \\
0,16 & 0,89 & 0,19 & 0,016 & 0,007 & 0,038 & 0,01 & 0,01 \\
\hline $\mathbf{N i}$ & Outros & $\mathbf{C E}^{1}$ & LE & LR & LE/LR & Alongamento \\
0,01 & 0,073 & 0,312 & $302 \mathrm{MPa}$ & $460 \mathrm{MPa}$ & 0,66 & $49 \%$ \\
\hline
\end{tabular}

${ }^{1} \mathrm{CE}$, segundo critério do Instituto Internacional de Soldagem (IIW). CE = Carbono Equivalente; LE = Limite de escoamento; $L R=$ Limite de resistência à tração.

para esse aço foi de $0,312 \%$, calculado de acordo com o critério do IIW, que dispensa o pré-aquecimento e o tratamento térmico após a soldagem [3].



(a)

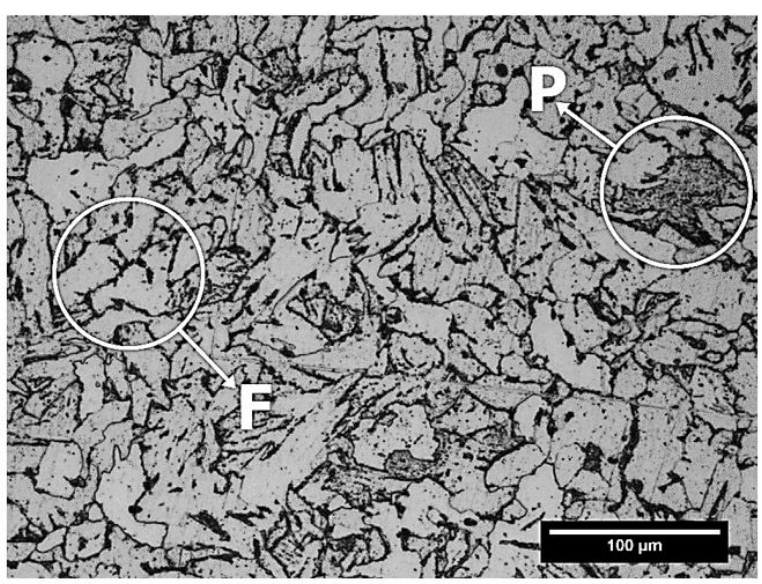

(b)

Figura 1. Metal de base do aço ASTM A-1018 em (a) menor e (b) maior magnificação, onde: F (ferrita) e P (perlita).

Como metal de adição foram utilizados fluxo e arame cuja classificação segundo American Welding Society (AWS) é AWS A5.17. Na fabricação foram utilizados dois arames, um interno com diâmetro de 2,4 mm e um externo com diâmetro de 3,2 mm. A Tabela 2 indica a composição química fornecida pelo fabricante do metal de solda depositado esperada e dos arames utilizados.

Tabela 2. Composição química esperada do metal depositado e dos arames utilizados fornecido pelo fabricante.

\begin{tabular}{lcccccc}
\hline & $\mathbf{C}$ & $\mathbf{M n}$ & $\mathbf{S i}$ & $\mathbf{P}$ & $\mathbf{S}$ & $\mathbf{C u}$ \\
Fluxo & 0,06 & 1,65 & 1,20 & 0,014 & 0,018 & 0,11 \\
Arame Externo $(\mathbf{3 , 2} \mathbf{~ m m})$ & 0,07 & 0,46 & 0,04 & 0,020 & 0,020 & 0,09 \\
Arame Interno $(\mathbf{2 , 4} \mathbf{~ m m})$ & 0,07 & 0,45 & 0,04 & 0,020 & 0,020 & 0,08 \\
\hline
\end{tabular}

Para soldagem foi utilizado o equipamento de patente PI0802712-9 A2 desenvolvida e fabricada pela empresa MEMPS, instalada em São Luís/MA. A máquina produz tubos com costura helicoidal pelo processo de soldagem por arco submerso (SAW) em campo com a utilização de dois arames de solda, sendo um interno e um externo, operados simultaneamente, conforme destacado na Figura 2. 


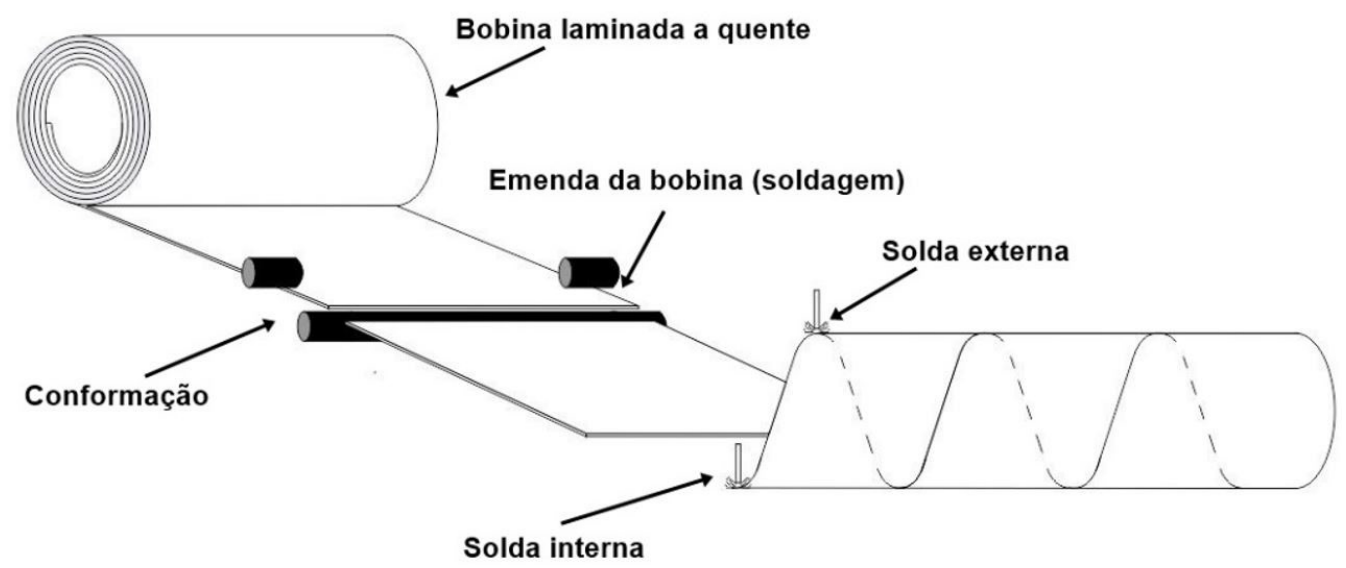

Figura 2. Esquema de fabricação de tubo helicoidal.

O processo de fabricação de tubos ocorre a partir da configuração da máquina para o ângulo correspondente ao diâmetro pretendido, e com o ajuste da calandra que efetuará a conformação da tira de aço. Em seguida, a bobina é instalada no desbobinador onde a chapa de aço é puxada para realizar o dimensionamento e corte da ponta, logo em seguida ela adquire o formato espiral de tubo dando início a fabricação. Simultaneamente são realizadas leituras do diâmetro interno, e caso seja identificado alguma incorreção no diâmetro pretendido, é feito o ajuste da calandra. Juntamente com o processo de correção é feita a verificação do posicionamento dos eletrodos interno e externo. Após a primeira volta de conformação da chapa inicia-se o processo de soldagem. Para este estudo, foram efetuadas duas soldas com dois arames operando simultaneamente, sendo um deles interno e outro externo, ambos em passe único. Estas foram executadas em posição plana (1G), com as tochas de soldagem permanecendo estacionárias enquanto o tubo girava. A solda interna foi iniciada (na posição 6 horas), e logo após com o avanço da soldagem, a solda externa se iniciou (posição 12 horas), realizada no mesmo ponto sendo esta pré-aquecida pelo passe interno. A diferença entre as soldas internas e externas é de aproximadamente 180 graus. Finalmente, quando o tubo atingiu o comprimento desejado, foi cortado e removido do equipamento e submetido à inspeção não destrutiva por ensaio visual de solda.

Na fabricação das amostras foi utilizada uma bobina de chapa de aço com 12,5 mm de espessura e $1200 \mathrm{~mm}$ de largura. Dessa forma, fabricaram-se dois tubos com diâmetro externo nominal de $1200 \mathrm{~mm}$ e comprimento de cinco metros. As principais diferenças na fabricação dos tubos soldados foram a velocidade e a diferença de corrente de soldagem entre a solda interna e externa, apresentados na Tabela 3.

Tabela 3. Parâmetros de soldagem utilizados nas soldas externa e interna).

\begin{tabular}{|c|c|c|c|c|c|c|}
\hline \multicolumn{3}{|c|}{ Identificação das Amostras } & \multirow{2}{*}{$\begin{array}{c}\text { Tensão (V) } \\
36\end{array}$} & \multirow{2}{*}{$\begin{array}{c}\text { Corrente (I) } \\
650\end{array}$} & \multirow{2}{*}{$\begin{array}{c}\begin{array}{c}\text { Vel. de } \\
\text { Soldagem } \\
\left.\text { (mm.min }^{-1}\right)\end{array} \\
800\end{array}$} & \multirow{2}{*}{ 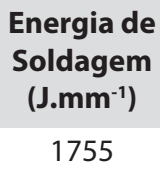 } \\
\hline Tubo 1 & Cordão Externo & Amostra $\mathrm{V}_{\mathrm{E} 800}$ & & & & \\
\hline & Cordão Interno & Amostra $\mathrm{V}_{1800}$ & 36 & 550 & 800 & 1485 \\
\hline \multirow[t]{2}{*}{ Tubo 2} & Cordão Externo & Amostra $\mathrm{V}_{\mathrm{E} 1600}$ & 36 & 550 & 1600 & 742,5 \\
\hline & Cordão Interno & Amostra $V_{11000}$ & 36 & 650 & 1600 & 877,5 \\
\hline
\end{tabular}

Em cada um dos tubos fabricados foi retirado uma amostra com as dimensões $300 \mathrm{~mm} \times 300 \mathrm{~mm}$ para confecção dos corpos de prova dos quais foram retiradas amostras no início e fim da chapa. Preparou-se os corpos de prova através de lixamento com lixas d'água de $\# 180$ a 1500, seguido de polimento com pasta de diamante de $3 \mu \mathrm{m}$ e $1 \mu \mathrm{m}$ e ataque químico com reagente nital $3 \%$ durante $15 \mathrm{~s}$. Realizou-se a caracterização da macro e microestrutura por estereoscopia, microscopia óptica (MO), composição química por espectrometria de emissão óptica (EEO) do cordão de solda e quantificação de microconstituintes por estereologia quantitativa por contagem de pontos. Para determinação do tamanho de grão da região de grãos grosseiros da ZTA (ZTAGG) utilizou-se o método de interceptos lineares conforme definido pela norma ASTM E-112-12 [19]. 
Os ensaios mecânicos consistiram de ensaio de dureza Vickers em escala micro com carga de 300 g, tempo de carga de 10 s e distância de ponto de indentação de $0,3 \mathrm{~mm}$, além de ensaio de dobramento em máquina universal, onde para cada condição foram retirados dois corpos de prova de seção retangular (Figura 3) para ser realizado o ensaio de dobramento de acordo com a norma ASME IX, conforme descrito na seção QW-462.3 (dobramento transversal de face).

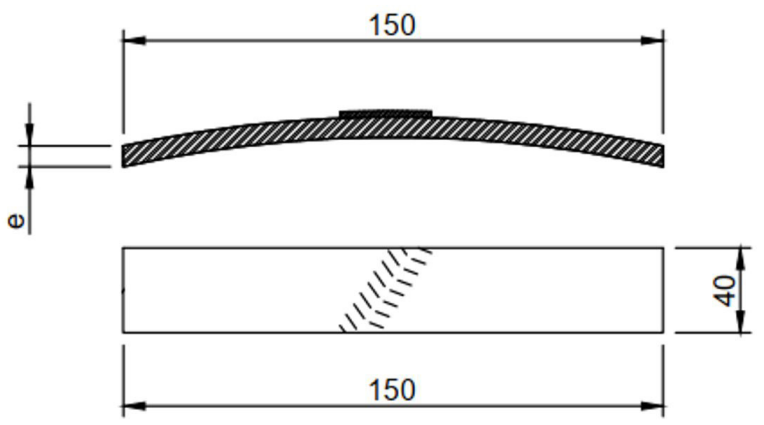

Figura 3. Croqui do corpo de prova de dobramento.

\section{Resultados e Discussão}

\subsection{Análise de macrografia}

A Figura 4 e 5 apresentam, respectivamente, a macrografia dos cordões de solda do Tubo 1 e Tubo 2.

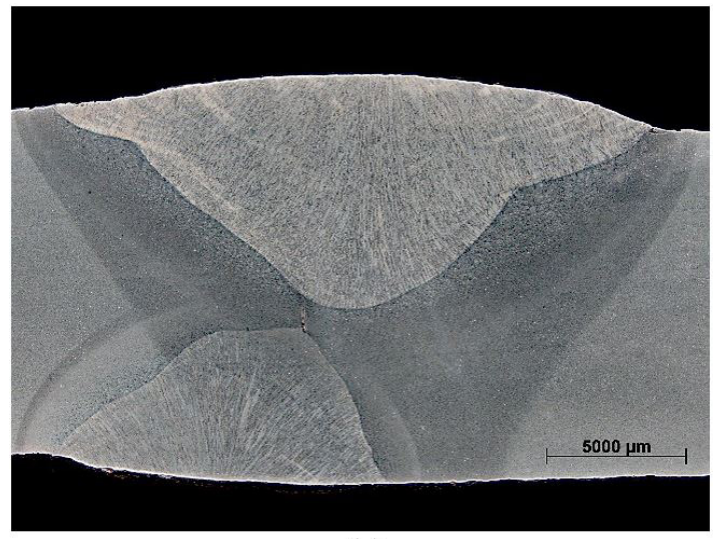

(a)



(b)

Figura 4. Macrografia do cordão de solda do corpo de prova do Tubo 1 (800 mm/min) - (a) início da amostra e (b) final da amostra.



(a)

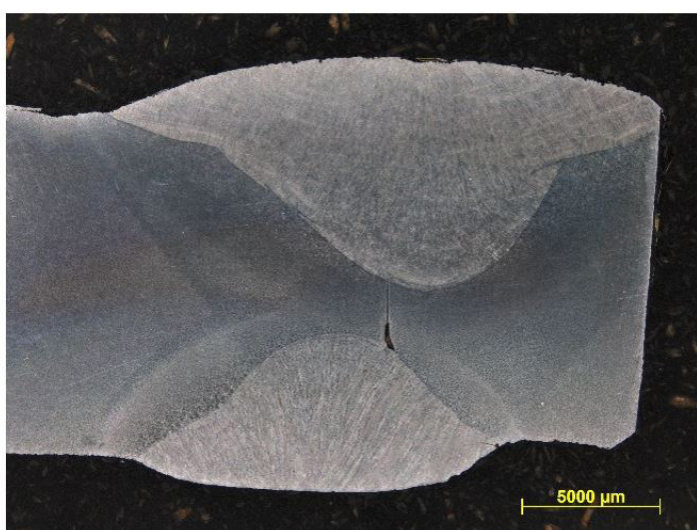

(b)

Figura 5. Macrografia do cordão de solda do corpo de prova do Tubo $2(1600 \mathrm{~mm} / \mathrm{min})$ - (a) início da amostra e (b) final da amostra. 
Soldagem Helicoidal de Tubos Produzida em Campo do Aço ASTM A-1018 e sua Correlação com Características Mecânicas e Microestruturais das Juntas Soldadas

Descontinuidades de soldagem do tipo mordeduras, porosidades e/ou trincas não foram detectadas em ambas as amostras. Entretanto, pode-se observar desalinhamento entre os cordões interno e externo. Esse desalinhamento é um problema que requer atenção por ter adicionado a esse fato a ausência de sobreposição entre os cordões internos e externos e, assim, falta de fusão. Em alguns casos, a falta de fusão associada ao desalinhamento dos cordões gera a falta de sobreposição. Tais problemas podem vir a ser um concentrador de tensão dependendo do esforço solicitante aplicado, contribuindo para a formação de trincas e para o envelhecimento precoce do cordão de solda [20-22]. Fazzini et al. [21] relacionam o desalinhamento e falta de fusão como características típicas de fonte de propagação de trincas que podem levar à fratura. Considera-se que o desalinhamento entre os cordões de solda uma característica relativa ao processo de soldagem pelo equipamento. Isto é influenciado pela forma com que o material é conformado para adquirir o formato para costura helicoidal e foi demonstrado nos estudos de Minnebruggen et al. [9] através do método de elementos finitos. Para Hertelé et al. [20], esse tipo de descontinuidade também é comum em soldagens circunferenciais. Outro fator que pode ser responsável pelo desalinhamento dos cordões de solda é a ausência de fixação e apara da borda da chapa antes da realização da soldagem nesse equipamento. Assim, implementar a apara das bordas e realizar o controle da largura da chapa pode ser uma maneira de mitigar o desalinhamento apresentado nas amostras.

Fazzini et al. [21] em seu trabalho sobre avaliação de fadiga nos tubos soldados em formato helicoidal identificaram o problema de desalinhamento entre as soldas interna e externa e as consequências que esse problema pode desencadear sobre a concentração de tensão. Já para Farhat [23] e Liu et al. [24], o desalinhamento entre os cordões de solda pode causar redução na resistência a impacto e influência na vida útil de fadiga. Porém, em alguns casos essa falta de alinhamento é considerada aceitável a depender da aplicação [25]. Kibey et al. [26], estudaram o efeito dessa descontinuidade em aços $X 60$ e X80, seus resultados indicaram que o desalinhamento tem influência significativa na capacidade de deformação a tração para os estados de limite plástico e fratura, porém para aplicações de esforço compressivo, como no caso de construção de camisas metálicas - onde esses tubos são empregados - aplicadas na indústria civil, em que estas camisas metálicas vão receber o concreto e estarem sobre compressão, tal desalinhamento é aceitável [23,25].

Para velocidade de soldagem foi constatado que com aumento (passando de $800 \mathrm{~mm} / \mathrm{min}$ para $1600 \mathrm{~mm} / \mathrm{min}$ ) houve um crescimento do comprimento da falta de penetração entre os cordões interno e externo, de aproximadamente $26 \%$ para a amostra do início da chapa e apenas 5,5\% para amostra do fim da chapa, conforme Figura 6 . Esse fato está associado às diferentes energias de soldagem, influenciado principalmente pela diferença de corrente de soldagem o que causou uma redução entre as energias de soldagem entre os cordões internos e externos do Tubo 1 e Tubo 2.

A diferença entre a área de penetração e reforço está diretamente ligada ao fato de possuírem diferenças de entrada de calor nos parâmetros estudados. De acordo com o trabalho de Kumar e Gupta [27], diversos autores como Kannan e Murugan [28], Kumanan et al. [29], Saluja e Moeed [30], Umrigar e Chaudhry [31] e Moshi et al. [32] reforçam a afirmativa de que a corrente é a variável mais importante dentre os parâmetros de soldagem. Do mesmo modo, pode-se afirmar que a diferença do diâmetro do arame é um fator importante na influência desses resultados, pois afeta a corrente de soldagem que será utilizada. Nota-se que os valores das áreas de reforço e penetração sofrem variações que seguem a relação de que a redução da área de penetração e aumento da área de reforço estão intimamente relacionados ao aumento de velocidade de soldagem quando se compara a junta completa (cordão interno e externo, simultaneamente). Outro fato é que essas diferenças podem estar relacionadas a execução desigual do processo de soldagem, como posicionamento desigual dos eletrodos e stick-out distintos. Fahrat [23] também obteve esse mesmo efeito, pelo menos na redução da área de penetração, quando se aumentou a velocidade de soldagem nos seus experimentos. Roy et al. [33] chegaram a essa mesma conclusão no que se refere ao comportamento da penetração, reforço, a largura do cordão com o aumento da corrente, ao aumentar a corrente de soldagem esses parâmetros também aumentam em proporção.

As diferenças entre os cordões internos e externos para um mesmo tubo são: corrente de soldagem e diâmetro do arame, visto que a velocidade de soldagem é mantida constante. Entre estes dois, pode-se supor, com base na literatura, a corrente de soldagem parece ser uma variável de maior influência na penetração do que o diâmetro do arame, bem como na geometria do cordão de solda, embora este tenha apresentado desalinhamento. Ainda que foi constatada falta de fusão devido ao desalinhamento nas juntas soldadas, os resultados de dobramento em ângulo de $180^{\circ}$ não apresentaram abertura da face. Abaixo, poderemos relacionar a microestrutura e a taxa de resfriamento para as duas condições apresentados de um mesmo tubo, indicando a importância da influência da corrente de soldagem. 


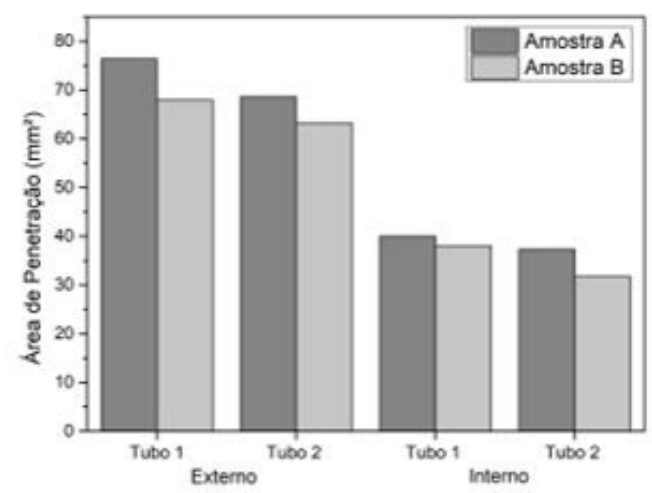

(a)

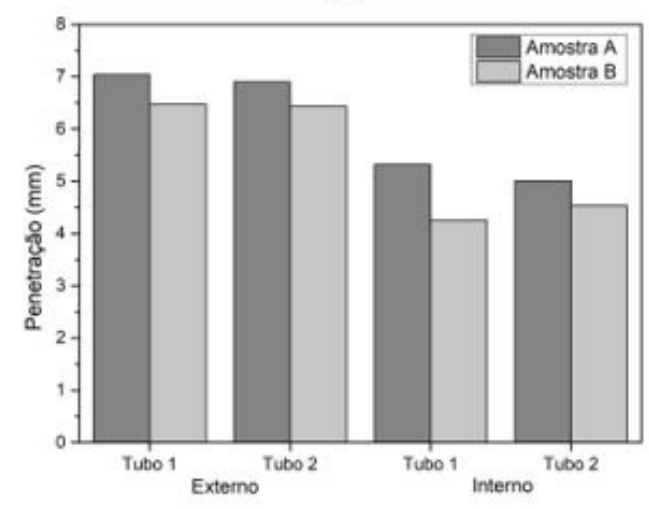

(c)

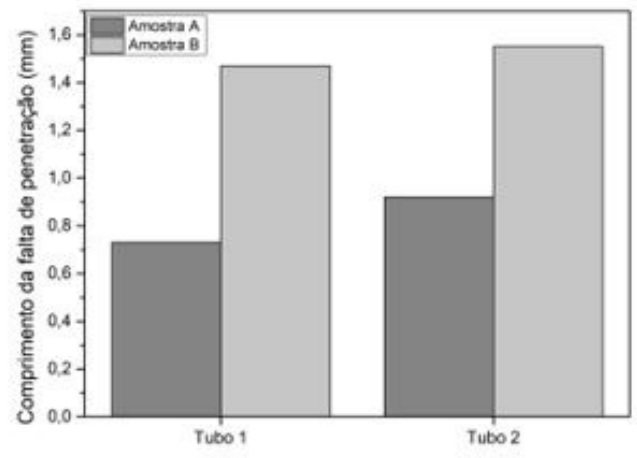

(e)

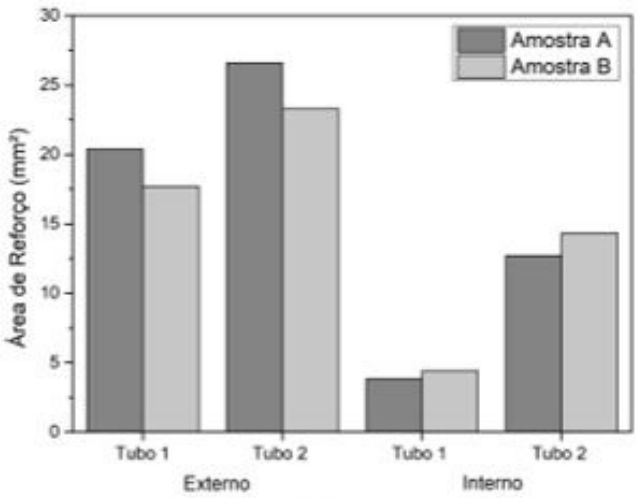

(b)

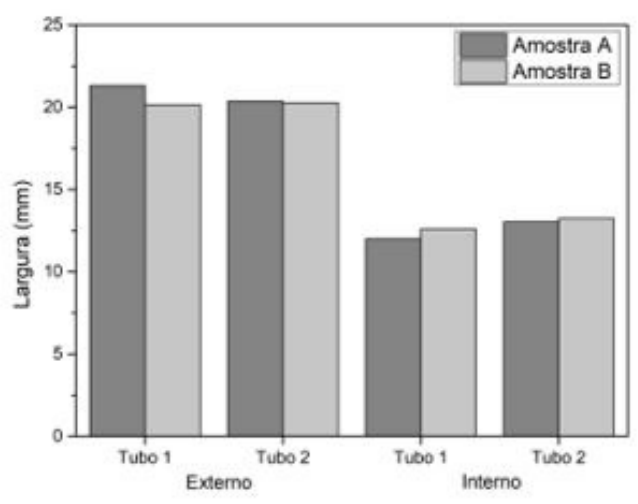

(d)

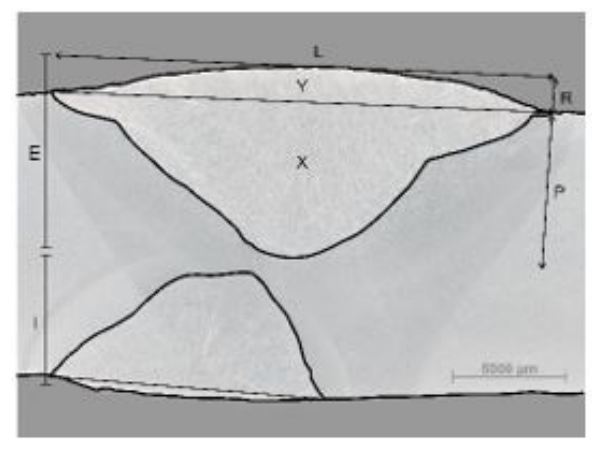

(f)

Figura 6. Medidas geométricas dos cordões de solda: (a) Área de penetração; (b) Área do reforço; (c) Penetração; (d) Largura (e) Comprimento da falta de penetração; e (f) Croqui do cordão de solda, onde: $\mathrm{L}=$ largura do cordão; $\mathrm{P}=$ penetração; $\mathrm{R}$ = altura do reforço; $\mathrm{Y}=$ área do reforço; $\mathrm{X}=$ área de penetração; $\mathrm{E}=$ cordão externo; $\mathrm{I}=$ = cordão interno.

\subsection{Caracterização microestrutural da zona fundida}

A avaliação mecânica e microestrutural da área do metal de solda é de suma importância, pois é considerada a região da junta que apresenta uma grande preocupação por, em alguns casos, apresentar resistência mecânica superior e tenacidade inferior ao metal de base [8,17], o que pode estar relacionado às fases e/ou constituintes presentes do metal de solda, mas também a defeitos geométricos e/ou de metalúrgicos. A análise de microscopia óptica corroborou a complexidade de microestruturas que podem estar presentes no cordão de solda de aços de baixo carbono, que em geral é composta por ferrita (e suas diferentes morfologias) e perlita [2,3]. As Figuras 7 e 8 apresentam as micrografias encontradas nos cordões de solda do Tubo 1 e Tubo 2, respectivamente. 


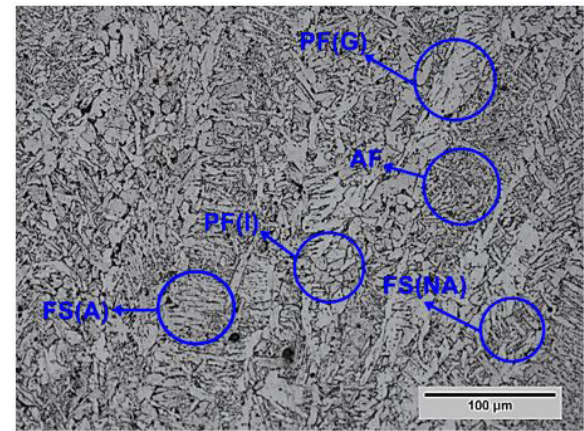

(a)



(c)

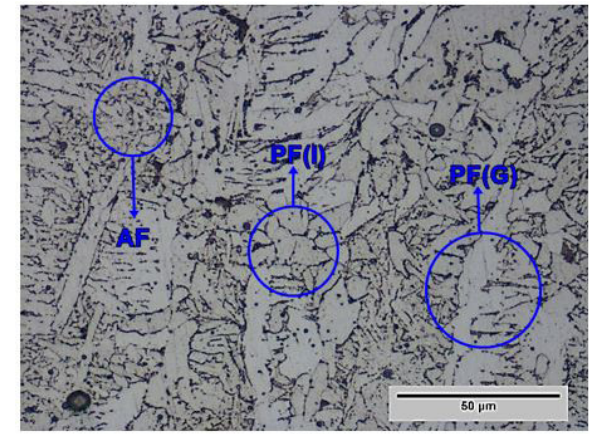

(b)

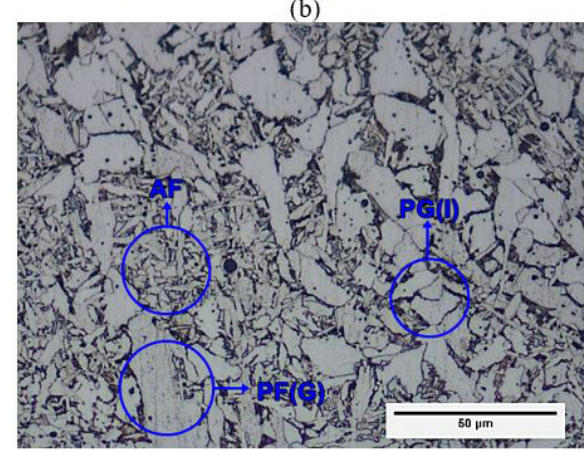

(d)

Figura 7. Micrografia do cordão de solda do Tubo 1-cordão interno (a) menor e (b) maior magnificação e cordão externo (c) menor e (d) maior magnificação. Onde: $A F=$ ferrita acicular; $P F(I)=$ ferrita primária intragranular; $P F(G)$ = ferrita primária de contorno de grão; $F S(A)$ = ferrita com segunda fase alinhada; $F S(N A)$ = ferrita com segunda fase não alinhada.



(a)

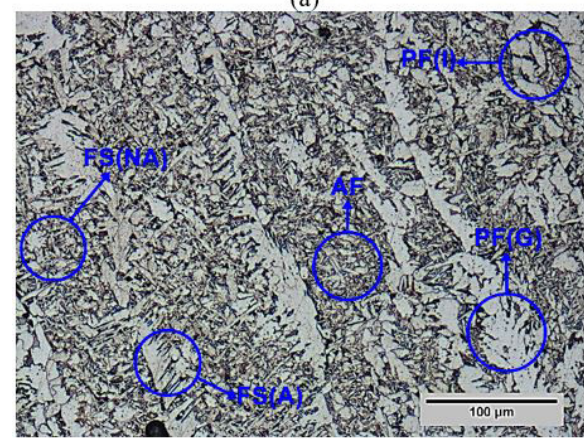

(c)



(b)



(d)

Figura 8. Micrografia do cordão de solda do Tubo 2 - cordão interno (a) menor e (b) maior magnificação e cordão externo (c) menor e (d) maior magnificação. Onde: $A F$ = ferrita acicular; $P F(I)=$ ferrita primária intragranular; $\operatorname{PF}(G)$ = ferrita primária de contorno de grão; $F S(A)$ = ferrita com segunda fase alinhada; $F S(N A)$ = ferrita com segunda fase não alinhada. 
$\mathrm{Na}$ avaliação da evolução microestrutural, os principais componentes identificados no cordão de solda dos Tubo 1 e 2 são ferrita primária de contorno de grão $(\operatorname{PF}(G))$; ferrita poligonal intragranular ( $\operatorname{PF}(I))$; ferrita com segunda fase não-alinhada ( $F S(N A))$; ferrita com segunda fase alinhada ( $F S(A)$ ) e principalmente o microconstituinte ferrita acicular (AF), o que condiz com as microestruturas encontrados na zona fundida de aços carbono soldados pelo processo a arco em um único passe, conforme literatura consultada [2,34,35]. As propriedades mecânicas dos aços estão fortemente ligadas as suas microestruturas [2,34]. Taxas de resfriamento maiores levam a redução dos grãos de ferrita e consequentemente ao aumento da resistência mecânica, enquanto taxas de resfriamento lentas levam a formação de ferrita primária que diminuem essa propriedade, pois possuem baixa resistência à propagação de trincas $[34,36,37]$. Os microconstituintes ferrita com segunda fase alinhada (FS(A)) e ferrita primária de contorno de grão $(P F(G))$ são definidos como as microestruturas a serem evitadas no metal de solda [17].

Jorge et al. [8], estudaram a influência do aumento do aporte térmico sobre as propriedades mecânicas e microestruturais em aço C-Mn, e obtiveram resultados que permitiram inferir que o aumento da energia de soldagem teve como consequência a redução de ferrita acicular acompanhada do aumento da ferrita primária e de agregados ferrita-carbonetos, fato que foi possível identificar nos cordões de solda do Tubo 1 e 2 . Ainda, de acordo com Lippold [2], Jorge et al. [8] e Thewlis [34], a melhoria das propriedades mecânicas de uma junta soldada, em especial a tenacidade, está associado a maior fração volumétrica de ferrita acicular presente, essa quantidade de AF depende da composição química do metal de solda e da taxa de resfriamento após a soldagem [36]. O favorecimento à tenacidade se deve ao fato desta fase não propiciar caminhos preferenciais à propagação de trincas, exigindo, ao contrário da ferrita primária de contorno de grão, grande dispêndio de energia para a propagação de uma trinca, na medida em que suas ripas de ferrita acicular obrigam a trinca a mudar de direção constantemente [34-37]. A composição química da zona fundida dos cordões de solda interno e externo em ambos os tubos é exposta na Tabela 4. As variações dos elementos de liga, principalmente do Si e Mn são menores no cordão interno. Observa-se que de acordo com a composição química apresentada os cordões externos apresentam valores acima do CE do metal de base, enquanto os CE dos cordões internos estão abaixo do apresentado pelo metal de base.

Tabela 4. Composição química e CE dos cordões de solda interno e externo.

\begin{tabular}{|c|c|c|c|c|}
\hline \multirow{2}{*}{ Composição Química } & \multicolumn{2}{|c|}{ Tubo 1} & \multicolumn{2}{|c|}{ Tubo 2} \\
\hline & Amostra $V_{E 800}$ & Amostra $V_{1800}$ & Amostra $V_{E 1600}$ & Amostra $V_{11600}$ \\
\hline$\% \mathrm{C}$ & 0,130 & 0,110 & 0,100 & 0,100 \\
\hline$\% \mathbf{S i}$ & 0,480 & 0,310 & 0,520 & 0,280 \\
\hline$\% M n$ & 1,270 & 1,000 & 1,200 & 0,900 \\
\hline \%P & 0,026 & 0,020 & 0,020 & 0,016 \\
\hline$\% S$ & 0,009 & 0,010 & 0,009 & 0,008 \\
\hline$\% \mathrm{Cr}$ & 0,010 & 0,010 & 0,010 & 0,010 \\
\hline$\% \mathrm{Ni}$ & 0,020 & 0,020 & 0,020 & 0,020 \\
\hline$\% \mathrm{Cu}$ & 0,020 & 0,020 & 0,030 & 0,010 \\
\hline \%Al & 0,017 & 0,016 & 0,015 & 0,015 \\
\hline$\% \mathrm{~V}$ & 0,001 & 0,001 & 0,001 & 0,001 \\
\hline $\mathrm{CE}_{\text {IIW }}(\%)$ & 0,346 & 0,281 & 0,371 & 0,254 \\
\hline
\end{tabular}

Analisando primeiramente a solda interna, observa-se que o aumento da velocidade de soldagem, e consequentemente da redução da energia de soldagem e em consequência aumento das taxas de resfriamento, favoreceu o aumento da fração volumétrica de ferrita acicular (AF) no metal de solda, conforme observado na Figura 9. Há também redução de ferrita primária (PF), proporcionada pelo aumento da AF. No metal de solda do Tubo 2 percebe-se que há presença de ferrita com segunda fase (FS) mesmo que em pequenas quantidades. Esse fato se justifica pela interação entre a redução da energia de soldagem e taxa de resfriamento, como comentado anteriormente. 


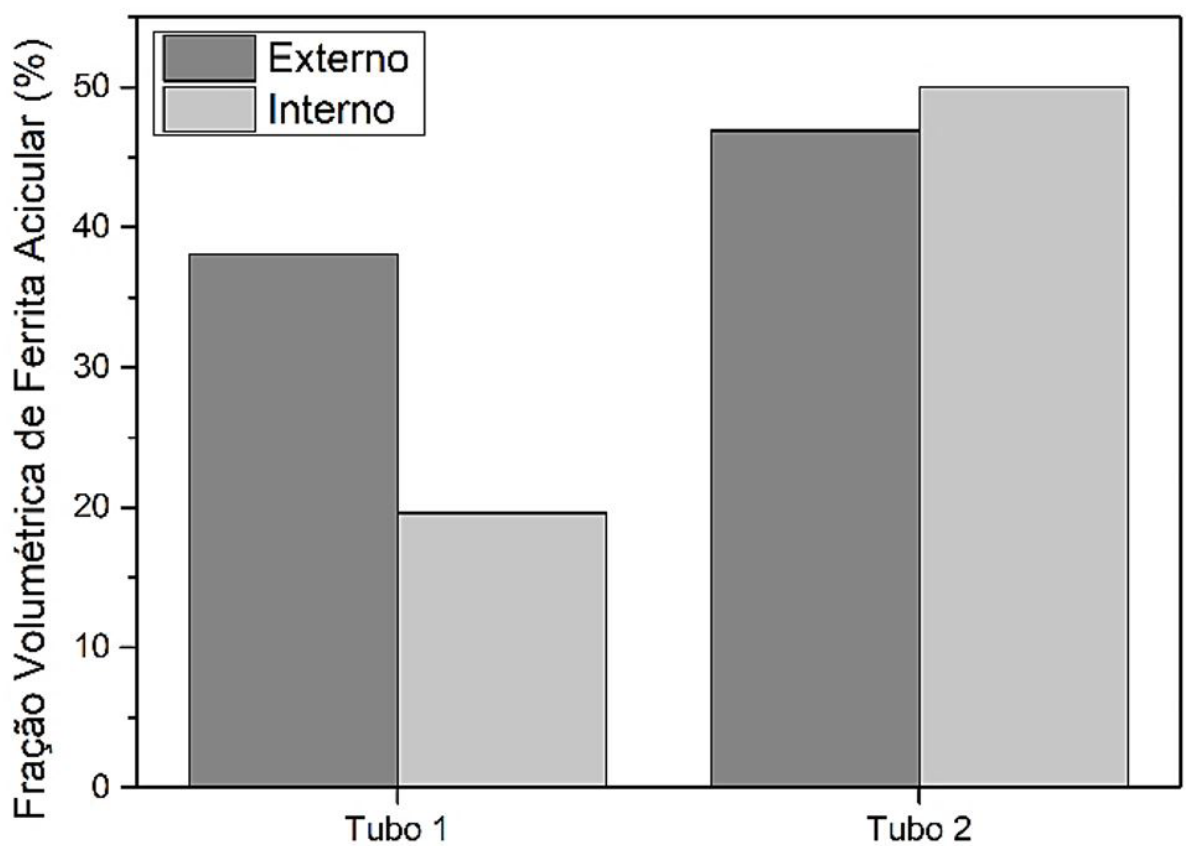

Figura 9. Fração volumétrica de AF nos cordões de solda dos Tubos 1 e 2.

Assim como a solda interna, a solda externa exibe a presença de ferrita acicular (AF) em quantidades crescentes com o aumento da velocidade, o que está associado ao menor aporte térmico e as taxas de resfriamento proporcionada por este. Comparando-se os cordões internos, entre eles há uma menor quantidade de ferrita com segunda fase (FS) e grande concentração do microconstituinte a ser evitado como ferrita primária de contorno de grão $(P F(G))$ [17], o que está associado a menor taxa de resfriamento e que denota a maior influência da corrente de soldagem nas diferenças apresentadas entre os cordões interno e externo, conforme já comentado acima.

Comparando-se os Tubos 1 e 2, considerando a relação de cordão interno com cordão interno e cordão externo com externo, uma vez que nesse caso, apenas a velocidade de soldagem foi alterada, nota-se a redução da PF(G), pois o Tubo 1 apresentou taxa de resfriamento mais lenta enquanto o Tubo 2, uma taxa mais rápida. A formação dessa microestrutura se dá a partir de taxas de resfriamento lenta. Com isso, a AF aumentou em proporção no Tubo $2[36,37]$. Isso implica afirmar que além da taxa de resfriamento, como mencionado anteriormente a composição do metal de adição e do metal de base propicia o surgimento da $\operatorname{AF}[2,37,38]$.

\subsection{Caracterização microestrutural da região de grãos grosseiros da ZTA}

Nas Figura 10 e 11 são apresentadas as microestruturas presentes na região de grãos grosseiros da ZTA, região mais próxima da zona fundida (conforme croqui apresentado na Figura 12). Na região de grãos grosseiros observa-se uma microestrutura bem distinta em relação a ZF, consistindo em uma ferrita de Widmanstätten que cresce a partir de uma ferrita primária em cordões externos. No entanto, para cordões internos, observa-se uma menor quantidade de ferrita de Widmanstätten com uma concentração maior de ferrita com segunda fase (FS). Normalmente, essa é a região da ZTA que possui a menor tenacidade, dureza elevada, e é um local comum para a formação de trincas [3,18,39].

A ZTA presente nas Figuras 10 e 11 é a ZTAGG com maiores grãos, uma vez que a mesma se encontra adjacente a zona fundida. Essa região foi escolhida por ser a mais crítica no sistema estudado, visto que não temos um aço ligado e precipitações deletérias não ocorrem em outras regiões da ZTA, fazendo da ZTAGG a mais preocupante. 




(a)

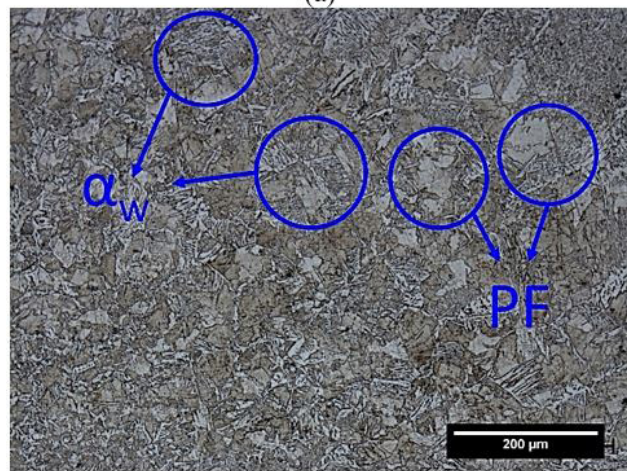

(c)

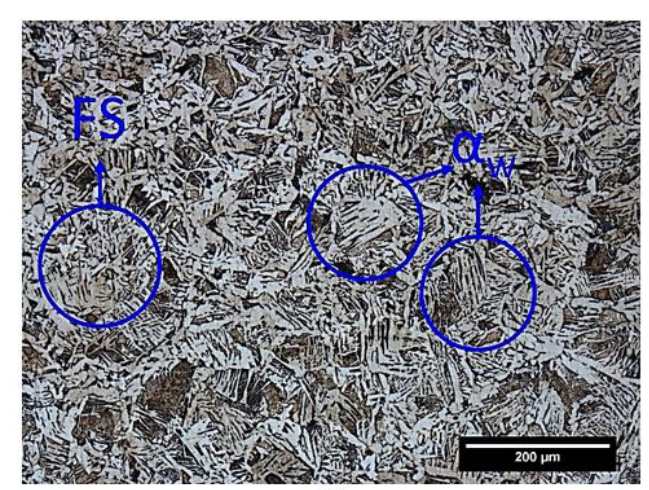

(b)

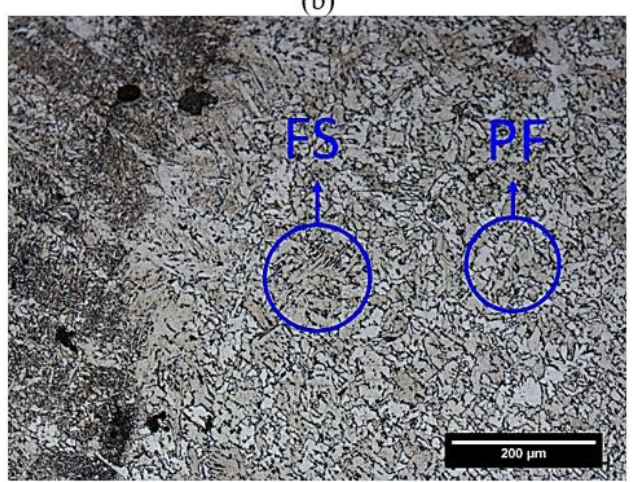

(d)

Figura 10. Região de grãos grosseiros do Tubo 1 - (a) e (b) ZTA Externa (c) e (d) ZTA Interna). Onde: FS = ferrita com segunda fase; PF = ferrita primária; $\alpha_{w}=$ ferrita de Widmanstätten.

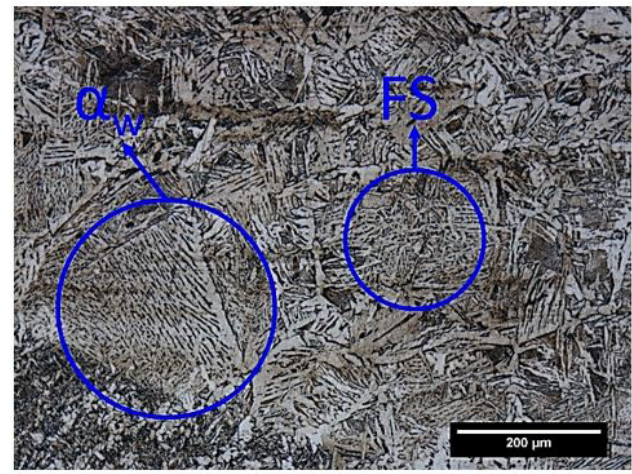

(a)

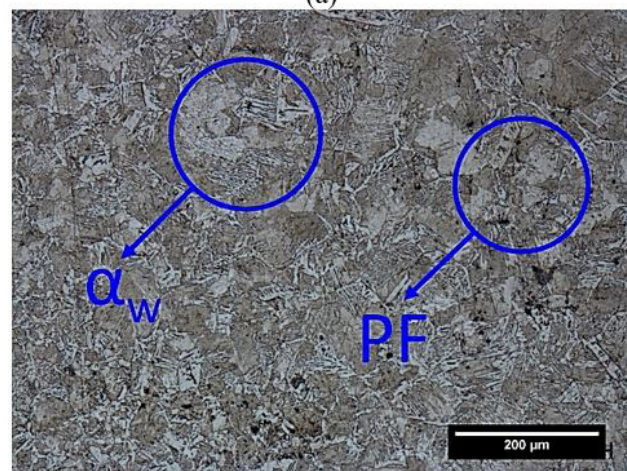

(c)



(b)

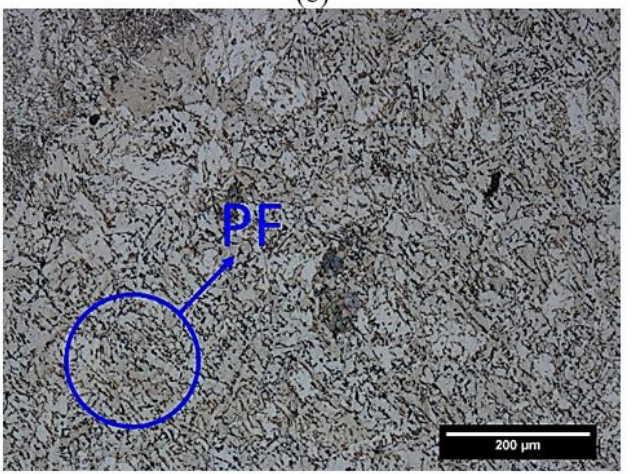

(d)

Figura 11. Região de grãos grosseiros do Tubo 2 - (a) e (b) ZTA Externa (c) e (d) ZTA Interna. Onde: FS = ferrita com segunda fase; $\mathrm{PF}=$ ferrita primária; $\alpha_{\mathrm{w}}=$ ferrita de Widmanstätten. 




Figura 12. Vista macro com identificação da região de análise da ZTAGG: (a) e (b) ZTA Externa; (c) e (d) ZTA Interna.

Ao avaliar o cordão interno (representado pela Figura 10c e 10d e Figura 11c e 11d), percebe-se a diferença entre as ZTAGG em relação ao cordão externo (representado pela Figura 10a e 10b e Figura 11a e 11b). O primeiro passe a ser realizado é o interno e possui menor aporte térmico, sendo assim, justifica-se o menor tamanho de grãos, além disso ele é reaquecido pelo passe externo, permitindo assim o refino dos grãos. Essa diferença foi quantificada de acordo com norma específica para medição de grãos (com representação esquemática na Figura 13) e o tamanho médio de grão é apresentado na Tabela 5.

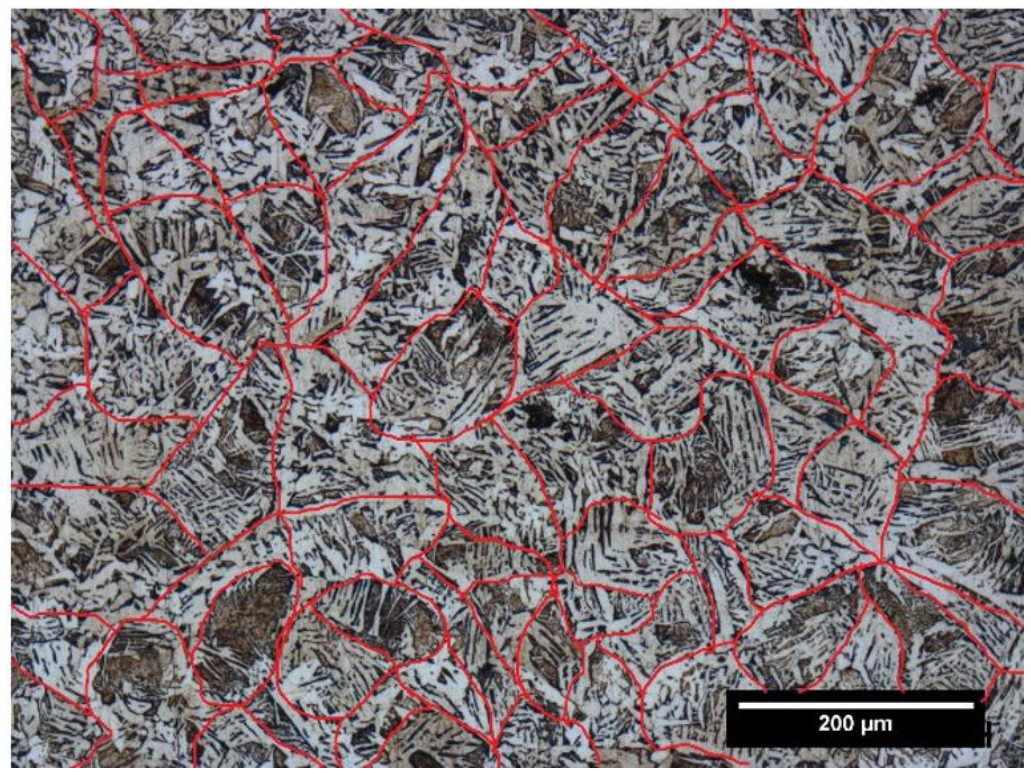

Figura 13. Representação esquemática da medição do tamanho de grão, conforme norma ASTM E112-12.

Tabela 5. Valor médio do tamanho de grão da ZTAGG ( $\mu$ m): (a) e (b) ZTA Externa e (c) e (d) ZTA Interna conforme ilustrado pela Figura 12.

\begin{tabular}{|c|c|c|c|c|}
\hline \multicolumn{5}{|c|}{ Tamanho de Grão $(\mu \mathrm{m})$} \\
\hline & \multicolumn{2}{|c|}{ ZTA Externa } & \multicolumn{2}{|c|}{ ZTA Interna } \\
\hline & (a) & (b) & (c) & (d) \\
\hline Tubo 1 & 86 & 68 & 58 & 48 \\
\hline Tubo 2 & 123 & 117 & 74 & 50 \\
\hline
\end{tabular}


As medidas encontradas reforçam a afirmativa de que o tamanho médio de grão do cordão externo é maior que o apresentado pelo cordão interno, fato relacionado à quantidade de energia imposta nos cordões de solda.

Outro comentário que se pode tecer é a respeito do aspecto da ZTA interna (conforme Figura 10d e Figura 11d), para os Tubos 1 e 2. A última se difere das demais por apresentar grãos com estrutura mais refinada - devido a influência térmica adicional pela execução do passe externo - modificando a microestrutura local, típico de soldagens multipasse [2,39].

Na literatura, autores como: Lippold [2], Modenesi et al. [16] e Albuquerque et al. [18] consideram que ZTA é a região crítica da junta soldada, mais especificamente a região de grãos grosseiros, por favorecer o surgimento de trincas. Segundo Albuquerque et al. [18], o aumento do tamanho de grão está entre os principais fatores metalúrgicos que contribuem para baixa tenacidade na região de grãos grosseiros da ZTA, podendo influenciar significativamente na resistência mecânica e na tenacidade da junta soldada. Gunaraj e Murugan [40] alertam sobre o impacto que a alta energia de soldagem, principalmente em soldagem por arco submerso, pode gerar na ZTA, como a fragilização por amolecimento. Uma maneira de conter esse problema seria reduzir a entrada de calor do processo de modo a manter a largura da zona crescimento e refino de grãos tão estreita quanto possível [18].

De modo geral, a região de grãos grosseiros apresenta microestrutura bastante semelhante, sendo a maioria de seus microconstituintes são ferrita de Widmanstätten acordando com os resultados encontrados por $[8,17,36]$.

\subsection{Perfil de dureza e ensaios de dobramento}

A Figura 14 exibe os resultados dos ensaios de dureza por microindentação realizados nas juntas soldadas das duas condições de aporte térmico, cordão interno e cordão externo, respectivamente, e nos dois tubos.

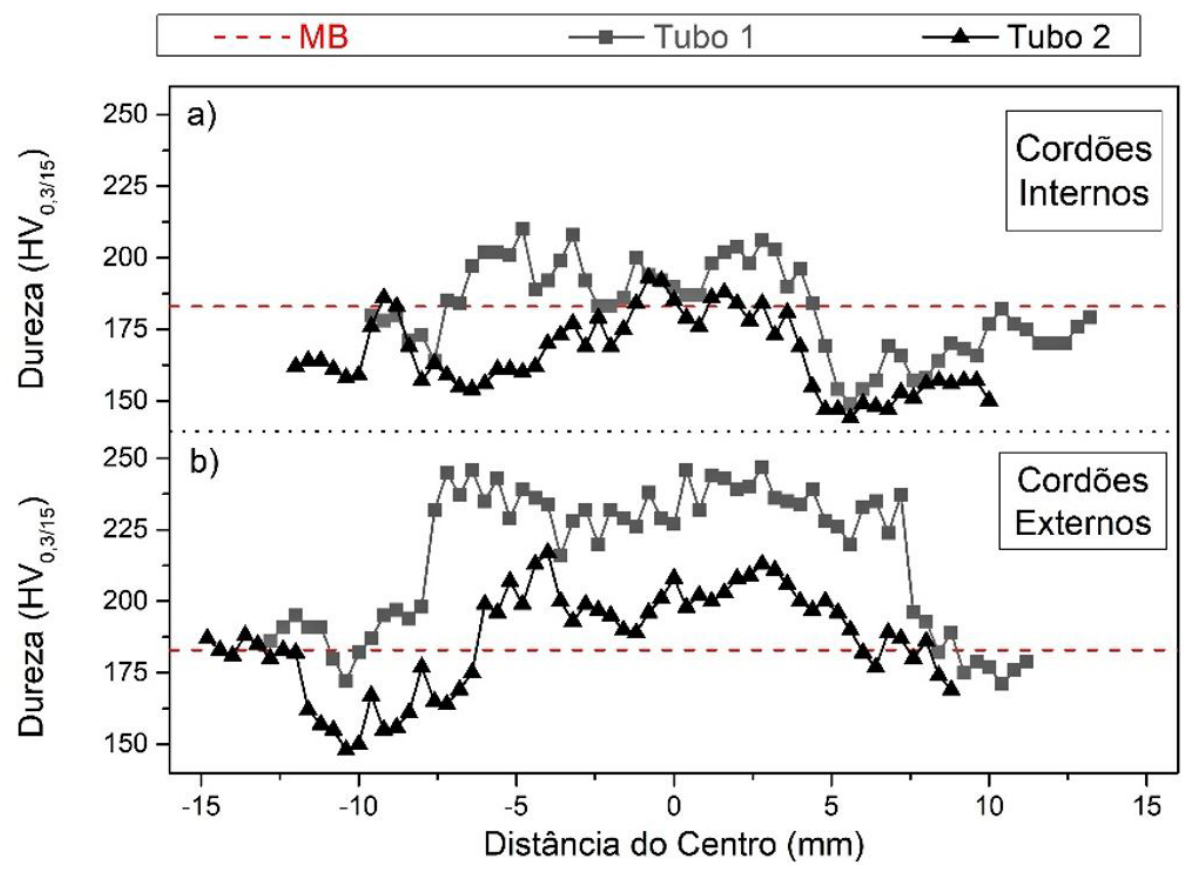

Figura 14. Perfil de dureza da secção transversal dos cordões do Tubo 1 e 2 (a) cordões internos; e (b) cordões externos.

Analisando os perfis de dureza, é perceptível que em média, os maiores valores de dureza se encontram na zona fundida dos cordões de solda. Esse comportamento é atribuído a presença das microestruturas aciculares formadas no decorrer da transformação ocorrida pelos ciclos térmicos impostos a junta soldada [18,23]. $O$ alto aporte térmico atingido durante a soldagem pelo processo de arco submerso levou ao amolecimento da ZTA a partir da zona de crescimento de grãos, como pode observado nos gráficos de dureza $[8,17,18]$. O resultado está em concordância com as microestruturas encontradas nessas regiões e discutidas previamente conforme $[17,18,23]$. 
Para os cordões externos, a zona fundida do Tubo 1 é a que apresenta maior valor de dureza. O maior valor pode estar relacionado a maior concentração do microconstituinte ferrita acicular. Os cordões internos, por sua vez, exibiram medidas de dureza inferiores as exibidas no cordão externo. Em todos os perfis os valores de dureza não ultrapassaram $260 \mathrm{HV}$, que é suficiente para afirmar que não há presença do microconstituinte martensita [2,3]. As médias de dureza da zona fundida são apresentadas na Figura 15.

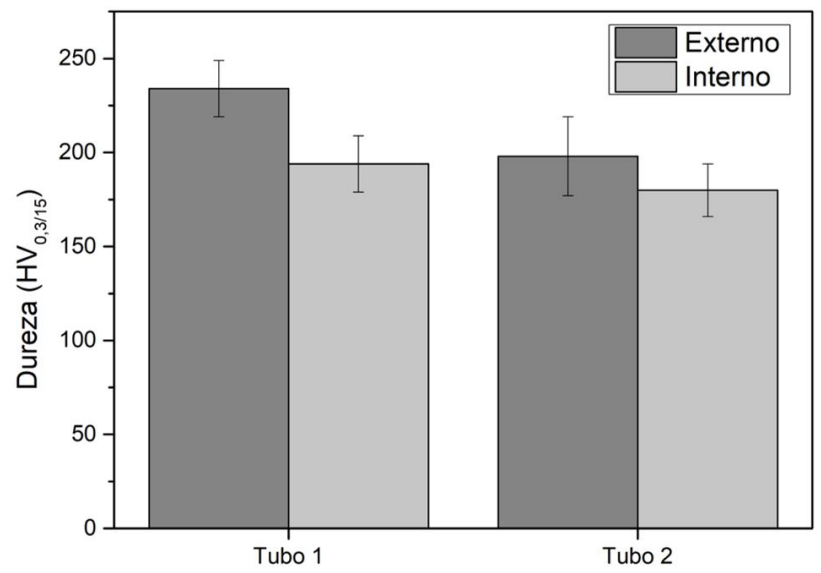

Figura 15. Média de dureza na zona fundida dos cordões interno e externo dos Tubos 1 e 2.

Sobre a ZTA, pode-se afirmar que apresentou comportamento semelhante ao apresentado na literatura [23,25]. Seus valores, em geral, foram inferiores aos medidos no metal de solda, devido às microestruturas presentes nessa região. Os principais microconstituintes presentes na ZTA foram a são ferrita de Widmanstätten e uma parcela de ferrita com segunda fase (FS), ambos os produtos formados a partir de baixas taxas de resfriamento e com menor dureza $[8,17]$.

A partir dessa análise, pode-se dizer que a dureza do material não depende apenas $\mathrm{CE}$, uma série de outros parâmetros devem ser analisados antes de se obter qualquer conclusão a cerca desse fato, dentre eles os tipos e propriedades dos consumíveis, os parâmetros de soldagem e os tratamentos térmicos sofridos pelo material.

A Figura 16 demostra o resultado obtido no ensaio de dobramento de face conforme norma ASME IX [41].

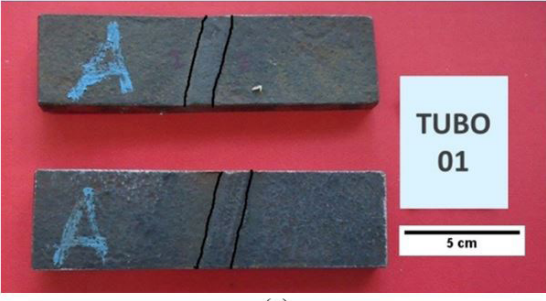

(a)



(c)

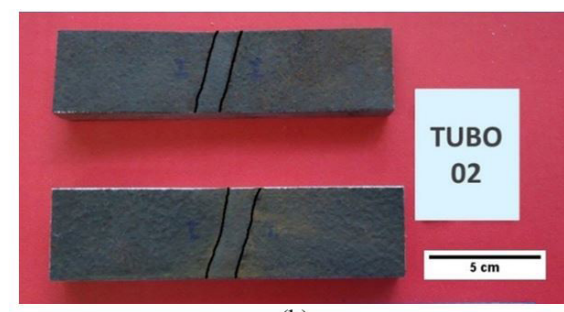

(b)

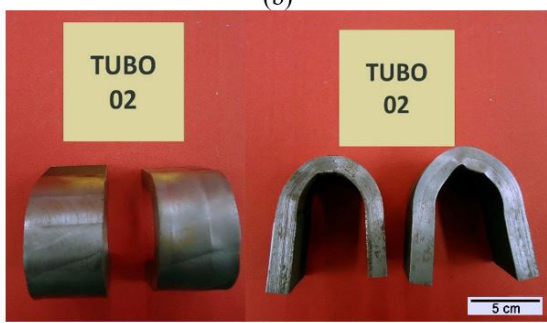

(d)

Figura 16. Corpos de prova do Tubo 1 (a) antes e (c) depois do ensaio de dobramento; Tubo 2 (b) antes e (d) depois de ensaio de dobramento. 
O ensaio de dobramento de face foi realizado para o cordão externo, ou seja, o último a ser realizado. De acordo com a ASME IX [41], para ser considerado aprovado o corpo de prova não deve apresentar descontinuidades maiores que $3,0 \mathrm{~mm}$. Nos resultados obtidos nenhum dos corpos de prova apresentaram descontinuidade e todos foram considerados aprovados. A partir desse resultado, pode-se inferir que apesar dos cordões apresentarem desalinhamento e falta de penetração completa não influenciou negativamente nos resultados.

\section{Conclusões}

As principais microestruturas encontradas nos cordões de solda com costura helicoidais produzidas em campo foram: ferrita acicular (AF), ferrita com segunda fase (FS) e ferrita primária (PF), sendo que a maior proporção foi o micronstituinte AF encontrado principalmente no metal de solda. As zonas termicamente afetadas, por sua vez, apresentaram como principais microconstituintes a ferrita de Widmanstätten nas regiões de grãos grosseiros tanto para o cordão interno como para o externo.

A geometria dos cordões de solda apresentou diferenças significativas nas áreas de penetração e reforço entre os cordões interno e externo que pode ser associado às diferenças de aporte térmico e ao diâmetro do arame, como se esperava. $O$ desalinhamento apresentado das amostras estudadas sugere que este fato seja uma característica do processo de soldagem utilizando o equipamento. Todavia, é importante destacar que, apesar da severidade das descontinuidades encontradas (falta de penetração e desalinhamento), a implementação de apara das bordas da bobina e uniformização das fontes de soldagem para o passe interno e externo do cordão de solda mitigariam estas descontinuidades, gerando um produto de qualidade superior e, para o presente estudo, essas descontinuidades foram consideradas aceitáveis para fabricação de tubos em campo.

Em relação ao desempenho mecânico nos ensaios de dobramento e na análise de dureza dos cordões é possível verificar que para ambas as condições de fabricação, mesmo com o desalinhamento dos cordões externo e interno e a falta de penetração, os cordões de solda apresentaram alto ângulo de dobramento e dureza superior ao metal de base indicando um aumento da resistência mecânica sem qualquer mecanismo fragilizante (precipitação deletéria, formação de martensita, dentre outros fatores).

Assim sendo, destaca-se a possibilidade de fabricação de tubos com costura helicoidal, diretamente no local onde serão utilizados, sem alterações significativas das condições controladas em laboratório. A fabricação de tubos por esse processo torna-se, portanto, uma alternativa atrativa nas atividades onde é requerida tubulações de grande diâmetro.

\section{Agradecimentos}

Os autores agradecem ao CNPq e FACEPE por concessão de bolsa e apoio financeiro, respectivamente; à MEMPS pela doação do material de estudo, suporte técnico e financeiro.

\section{Referências}

[1] American Society for Metals. Handbook ASM: welding, brazing, and soldering. Vol. 6. Materials Park: ASM International; 1993.

[2] Lippold JC. Welding metallurgy and weldability. Hoboken: John Wiley \& Sons; 2014

[3] Modenesi PJ, Marques PV, Bracarense AQ. Soldagem: fundamentos e tecnologia. Belo Horizonte: Editora UFMG; 2005.

[4] Singh RP, Garg RK, Shukla DK. Parametric effect on mechanical properties in submerged arc welding process: a review. International Journal of Engineering Science and Technology. 2012;4(2):11.

[5] Marouço ES, Diniz JLC, Santos OR, Souza LFG, Jorge JCF. Estudo do aporte térmico nas propriedades mecânicas de metais de solda de aço C-Mn obtidos pelo processo arco submerso. Tecnologica em Metalurgia, Materiais e Mineração. 2013;10(2):128-137. http://dx.doi.org/10.4322/tmm.2013.018.
[6] Barros JFC Jr. Aumento da velocidade de soldagem para processo de arco submerso em juntas de um tubo de aço API X70 [dissertação de mestrado]. Guaratinguetá: Universidade Estadual Paulista; 2009.

[7] Soeiro JC Jr, Rocha DB, Brandi SD. Uma breve revisão histórica do desenvolvimento da soldagem dos aços API para tubulações. Soldagem e Inspeção. 2013;18(2):176-195. http://dx.doi. org/10.1590/S0104-92242013000200011.

[8] Jorge JCF, Souza LFG, Marouco ES, Santos OR Fo, Diniz JLC. Propriedades mecânicas e microestruturais de juntas soldadas pelo processo a arco submerso com elevado aporte térmico. Soldagem e Inspeção. 2015;20(3):347-358. http://dx.doi. org/10.1590/0104-9224/SI2004.04.

[9] Van Minnebruggen K, De Waele W, Denys R, Thibaux P. Strain based design considerations for spiral welded pipelines. In: Hertelé S, editor. Sustainable construction and design. Ghent: Laboratory Soete,Ghent University; 2012. p. 44-51. 
[10] Ribeiro ACN. Avaliação da soldagem do aço naval AH36 microligado soldado pelo processo arco submerso com um e dois arames [dissertação de mestrado]. São Paulo: Departamento de Engenharia Metalúrgica e de Materiais, Universidade de São Paulo; 2015. http://dx.doi.org/10.11606/D.3.2015.tde-16112015002331 .

[11] Forouzan MR, Mirfalah Nasiri SM, Mokhtari A, Heidari A Golestaneh SJ. Residual stress prediction in submerged arc welded spiral pipes. Materials \& Design. 2012;33:384-394. http://dx.doi.org/10.1016/j.matdes.2011.04.016.

[12] Alobaidi W, Sandgren E. Detection of defects in spiral/helical pipes using RF technology. In: Proceedings of the 11th Pipeline Technology Conference; 2016; Berlin. Berlin: PTC; 2016. p. 22-33.

[13] Sadowski AJ, Rotter JM. Modelling and behaviour of cylindrical shell structures with helical features. Computers \& Structures. 2014;133:90-102. http://dx.doi.org/10.1016/j. compstruc.2013.11.012.

[14] Oliveira EP, Madeira I. Fábrica móvel de tubo helicoidal de chapa. PI0802712-9 A2. 2008 Julho 25.

[15] Aslani F, Uy B, Hur J, Carino P. Behaviour and design of hollow and concrete-filled spiral welded steel tube columns subjected to axial compression. Journal of Constructional Steel Research. 2017;128:261-288. http://dx.doi.org/10.1016/j.jcsr.2016.08.023.

[16] Modenesi PJ, Marques PV, Santos DB. Introdução à metalurgia da soldagem. Belo Horizonte: UFMG; 2012.

[17] Albuquerque SF, Maciel TM, Santos MA, Bracarense AQ. Avaliação da microestrutura e propriedades mecânicas de metais de solda obtidos por processos de soldagem manual e automatizado utilizado na soldagem de aço API $5 \mathrm{~L}$ X80. Soldagem e Inspeção. 2011;16(4):322-332. http://dx.doi.org/10.1590/ S0104-92242011000400003.

[18] Albuquerque SF, Silva RS, Maciel TM, Almeida DM, Bracarense AQ. Estudo do comportamento do aço API $5 \mathrm{~L}$ X80 quando submetido à soldagem por processo automatizado. Soldagem e Inspeção. 2012;17(2):137-146. http://dx.doi.org/10.1590/ S0104-92242012000200007.

[19] American Society for Testing and Materials. ASTM E112-12: standard test methods for determining average grain size. West Conshohocken: ASTM.

[20] Hertelé S, Cosham A, Roovers P. Structural integrity of corroded girth welds in vintage steel pipelines. Engineering Structures. 2016;124:429-441. http://dx.doi.org/10.1016/j. engstruct.2016.06.045.

[21] Fazzini PG, Belmonte J, Chapetti M, Otegui J. Fatigue assessment of a double submerged arc welded gas pipeline. International Journal of Fatigue. 2007;29(6):1115-1124. http://dx.doi. org/10.1016/j.ijfatigue.2006.09.013.

[22] Lotsberg I. Stress concentrations due to misalignment at butt welds in plated structures and at girth welds in tubulars. International Journal of Fatigue. 2009;31(8-9):1337-1345. http:// dx.doi.org/10.1016/j.ijfatigue.2009.03.005.

[23] Farhat $H$. Effects of multiple wires and welding speed on the microstructures and properties of submerged arc welded X80 steel [tese de doutorado]. Saskatoon: University of Saskatchewan; 2007.

[24] Liu X, Song W, Yan Z, Qiang W, pan H. Misalignment effect on stress concentration of thickness mismatched plate structures. Procedia Structural Integrity. 2016;2:2038-2045. http://dx.doi. org/10.1016/j.prostr.2016.06.256.

[25] Rodríguez-Martín M, Rodríguez-Gonzálvez P, Lagüela S, GonzálezAguilera D. Macro-photogrammetry as a tool for the accurate measurement of three-dimensional misalignment in welding.
Automation in Construction. 2016;71:189-197. http://dx.doi. org/10.1016/j.autcon.2016.08.016.

[26] Kibey SA, Minnaar K, Issa J, Gioielli PC. Effect of misalignment on the tensile strain capacity of welded pipelines. In: Proceedings of the 18th International Offshore and Polar Engineering Conference; 2008; Vancouver. California: International Society of Offshore and Polar Engineers; 2008.

[27] Kumar S, Gupta ED. optimization of submerged arc welding parameters for joining dissimilar materials using Taguchi Method. International Journal of Aerospace and Mechanical Engineering. 2017;4(1):1-3.

[28] Kannan T, Murugan N. Effect of flux cored arc welding process parameters on duplex stainless steel clad quality. Journal of Materials Processing Technology. 2006;176(1-3):230-239. http:// dx.doi.org/10.1016/j.jmatprotec.2006.03.157.

[29] Kumanan S, Dhas JER, Gowthaman K. Determination of SAW process parameters using Taguchi method and Regression analysis. Indian Journal of Engineering and Materials Sciences. 2007;14:177-183.

[30] Saluja R, Moeed KM. Modeling and parametric optimization using factorial design approach of submerged arc bead geometry for butt joint. International Journal of Engineering Research and Applications. 2012;2(3):505-508.

[31] Umrigar P, Chaudhry S. Parametric optimization of SAW on SS-304. International Journal for Technological Research in Engineering. 2014;1(11):1285-1293.

[32] Moshi AM, Bharthi SR, Rajeshkumar R, Kumar R. Factors influencing submerged arc welding on stainless steel: a review. Journal of Engineering and Applied Sciences. 2016;11(2):12371241.

[33] Roy J, Majumder A, Rai RN, Saha SC. Study the influence of heat input on the shape factors and HAZ width during submerged arc welding. Indian Welding Journal. 2015;48(1):51-55. http:// dx.doi.org/10.22486/iwj/2015/v48/i1/125962.

[34] Thewlis G. Classification and quantification of microstructures in steels. Materials Science and Technology. 2004;20(2):143 160. http://dx.doi.org/10.1179/026708304225010325.

[35] Krauss G, Thompson SW. Ferritic microstructures in continuously cooled low-and ultralow-carbon steels. ISIJ International. 1995;35(8):937-945. http://dx.doi.org/10.2355/ isijinternational.35.937.

[36] Santos TFA, Lopez EAT, Vilela JMC, Andrade MS, Cota AB. Caracterização microestrutural de aços baixo carbono por microscopia de força atômica. Revista Latinoamericana de Metalurgia y Materiales. 2015;35(1):118-133.

[37] Babu SS, David SA. Inclusion formation and microstructure evolution in low alloy steel welds. ISIJ International. 2002;42(12):13441353. http://dx.doi.org/10.2355/isijinternational.42.1344.

[38] Evans GM. The effect of carbon on the microstructure and properties of C-Mn all-weld metal deposits. Welding Research Abroad. 1983;19(1):13-24.

[39] MoeinifarS, Kokabi AH, Hosseini HRM. Role of tandem submerged arc welding thermal cycles on properties of the heat affected zone in X80 microalloyed pipe line steel. Journal of Materials Processing Technology. 2011;211(3):368-375. http://dx.doi. org/10.1016/j.jmatprotec.2010.10.011.

[40] Gunaraj V, Murugan N. Prediction of heat-affected zone characteristics in submerged arc welding of structural steel pipes. Welding Journal. 2002;81(3):45.

[41] American Society of Mechanical Engineers. ASME IX: qualification standard for welding and brazing procedures, welders, brazers, and welding and brazing operators. New York: ASME; 2013. 